\title{
Anti-IL-4 Treatment at Immunization Modulates Cytokine Expression, Reduces IIIness, and Increases Cytotoxic T Lymphocyte Activity in Mice Challenged with Respiratory Syncytial Virus
}

\author{
Yi-Wei Tang and Barney S. Graham \\ Department of Medicine, and Microbiology and Immunology, Vanderbilt University School of Medicine, \\ Nashville, Tennessee 37232-2605
}

\begin{abstract}
Upon respiratory syncytial virus ( $R S V)$ challenge, mice previously immunized intramuscularly with inactivated whole virus express a Th2-like pattern of cytokine mRNA, while mice immunized with live virus intranasally express a Th1like pattern. In this study, we evaluated the effects of antiIL-4 treatment on the induction of immune responses after immunization. Mice treated with anti-IL-4 at the time of immunization with inactivated $\mathrm{RSV}$ had reduced clinical illness after live virus challenge, as measured by weight loss, illness score, and virus replication. This was associated with an augmented CD8 + cytotoxic T lymphocyte (CTL) activity, increased expression of IFN- $\gamma$ mRNA relative to IL-4 mRNA, and a higher titer of RSV-specific IgG $_{2 \mathrm{a}}$ in the antiIL-4 treated mice before challenge. Anti-IL-4 administration at the time of challenge had no effects on illness, immunoglobulin isotype, or cytokine patterns. These results suggest that inhibition of IL-4 action at immunization can shift the selective activation of lymphocytes to a more Th1-like response. This cytokine milieu is associated with augmented CTL activity, which may be the factor responsible for rapid viral clearance and reduced illness at the time of remote RSV challenge. (J. Clin. Invest. 1994. 94:1953-1958.) Key words: pathogenesis • vaccine • antibody • T helper lymphocytes
\end{abstract}

\section{Introduction}

Respiratory syncytial virus (RSV) ${ }^{1}$ is an important cause of respiratory illness in children and adults. A formalin-inactivated, alum-precipitated whole RSV vaccine preparation given intramuscularly did not protect children from infection. Moreover, the illness accompanying subsequent infection was unusually severe, with some deaths and an increased rate of hospitalization (1-4). In contrast, clinical trials of live attenuated RSV vaccine products, such as temperature-sensitive mutants $(5,6)$

Address correspondence to Barney S. Graham, MD, PhD, A-3310 Medical Center North, Vanderbilt University School of Medicine, Nashville, TN 37232-2605.

Received for publication 2 June 1994 and in revised form 21 June 1994.

1. Abbreviations used in this paper: CTL, CD8+ cytotoxic T lymphocyte; RSV, respiratory syncytial virus.

J. Clin. Invest.

(C) The American Society for Clinical Investigation, Inc. 0021-9738/94/11/1953/06 \$2.00

Volume 94, November 1994, 1953-1958 or cold-adapted strains $(7,8)$, did not result in enhanced illness, but had limited success because of reversion to wild type virulence or lack of immunogenicity.

Recently, murine $\mathrm{T}$ helper cells have been subdivided into two distinct subsets on the basis of their patterns of cytokine secretion: Th1 cells, expressing interleukin 2 (IL-2), interferon$\gamma($ IFN- $\gamma)$, and tumor necrosis factor- $\beta$ (TNF- $\beta$ ), mediate delayed-type hypersensitivity, while Th2 cells, expressing IL-4, IL-5, IL-6, and IL-10, provide efficient help for antibody-producing lymphocytes $(9,10)$. Different subsets of T-helper cells have been reported to determine disease expression through the release of different cytokines (11). In general, immunization that leads to a dominant IL-4 response from T cells is associated with disease progression, while immunization which leads to dominant IFN- $\gamma$ production is protective (10). This pattern of IFN- $\gamma$-associated protection and IL-4-associated disease progression has been noted in Leishmania major (12), Toxoplasma gondii (13), Schistosoma mansoni (14), Candida albicans (15), and the murine acquired immunodeficiency syndrome (16) in mouse models, and leprosy (17), measles (18), and AIDS (19) in humans.

It has been shown previously that CD4+ T lymphocyte depletion before rechallenge of mice with RSV prevents the development of lymphocytic aggregates and pathology in lungs $(20,21)$. Recent evidence suggests that the CD4+ T lymphocytes determine the pathological events through their patterns of cytokine secretion. It has been reported that $T$ cell lines with distinct patterns of cytokine expression can be derived from mice immunized with recombinant vaccinia expressing individual RSV proteins (22). We have recently found that priming with RSV antigens produces distinct patterns of pathology and cytokine mRNA expression after RSV challenge of mice. Upon RSV challenge, mice previously immunized intramuscularly with inactivated virus produced a dominant Th2-like pattern of cytokine expression. In contrast, challenge of mice immunized with live RSV by either mucosal or parenteral routes produced a Th1-like pattern (23). These findings have suggested a potential mechanism for the pathogenesis of RSV vaccine-enhanced illness: RSV immunization can selectively activate subpopulations of lymphocytes which, upon rechallenge, result in different levels of illness expression based on cytokine secretion patterns.

Others have shown that blocking Th2 cytokine expression, either by administering an IL-4 neutralizing antibody $(24,25)$ or disrupting the IL-4 gene $(26,16)$, can result in diminished IL-4 production and improved disease outcome in models of other infectious diseases. In contrast, treatment with anti-IFN$\gamma$ can result in a more Th2-like immune response causing increased mortality (15). We report here that a brief treatment of mice with anti-IL-4 at the time of whole inactivated RSV immunization results in diminished illness and more rapid viral clearance after subsequent live RSV challenge. This was associ- 
ated with an augmented CD8+ cytotoxic T lymphocyte (CTL) activity in lungs and a shift from a Th2-like to a more Th1-like pattern of cytokine expression.

\section{Methods}

Mice, virus, monoclonal antibody, and illness assessment. Pathogenfree female BALB/c mice, 8-10 mo old, were purchased from Charles River Laboratories (Raleigh, NC) and cared for according to the "Guide for the Care and Use of Laboratory Animals" as previously described (27). Preparation of the formalin-inactivated, alum-precipitated RSV (23) and preparation of stock of the A2 strain of RSV (28) have been previously reported. Both the vaccine preparation and the challenge stock of RSV were derived from the A2 strain of RSV. An IL-4neutralizing monoclonal antibody $(11 \mathrm{~B} 11,29)$ was administered at 200 $\mu \mathrm{g} /$ dose i.p. Control mice received PBS on the same schedule. Each mouse was immunized with formalin-inactivated, alum-precipitated RSV containing $2.2 \times 10^{6}$ pfu equivalents of virus antigen intramuscularly, and challenged with $10^{7} \mathrm{pfu}$ of live RSV intranasally 4 wk later as previously described (23). The clinical data, including weight change and illness score following challenge, were obtained by weighing on a digital scale and by appearance. Clinical illness score was assigned by a blinded examiner using an index derived by assigning numbers to a set of clinical features seen in mice with different degrees of illness: 0 healthy; 1-barely ruffled fur; 2-ruffled fur, but active; 3-ruffled fur and inactive; 4-ruffled, inactive, hunched posture, and gaunt; 5-dead.

Plaque assays and neutralization tests. The lung tissue was removed and quick-frozen in Eagle's minimal essential media containing $10 \%$ fetal bovine serum (10\% EMEM). Thawed tissues were kept chilled while individually ground. Dilutions of the clarified supernatant were inoculated on 2-d-old HEp-2 monolayers, $80 \%$ confluent in Costar 12well plates under $0.75 \%$ methylcellulose in $10 \%$ EMEM. After incubation for $4 \mathrm{~d}$ at $37^{\circ} \mathrm{C}$, the monolayers were fixed, stained with hematoxylin-eosin, and plaques were counted under a dissecting microscope. Plaque-reduction neutralization assays were performed by mixing dilutions of heat-inactivated serum starting at 1:40 with equal volumes of titered virus stock for $1 \mathrm{~h}$ at room temperature with and without complement. The serum dilution producing $60 \%$ plaque reduction was calculated by linear regression and considered as neutralization titer (27).

$R S V$-specific Ig isotype ELISA. BCH4, a persistently RSV-infected $\mathrm{BALB} / \mathrm{c}$ fibroblast cell line, as well as $\mathrm{BC}$, its parent cell line, were bound to the solid phase on Immulon II 96-well plates (Nunc, Roskilde, Denmark). Plates were dried in a Speedvac (Savant, Instrs., Inc., Farmingdale, NY), blocked with $1 \%$ gelatin in PBS, and washed with PBS containing $0.5 \%$ Tween. $100 \mu \mathrm{l}$ of two-fold serial diluted mouse serum samples, starting at dilution of $1: 40$, were added to each well. Plates were incubated at $37^{\circ} \mathrm{C}$ for $60 \mathrm{~min}$, washed, and $100 \mu \mathrm{l}$ of goat antimurine IgA, IgE, $\operatorname{IgG}_{1}, \mathrm{IgG}_{2 \mathrm{a}}, \mathrm{IgG}_{3}$, or total Ig conjugated to alkaline phosphatase (Southern Biotechnology, Birmingham, AL) diluted 1:1000 was added, respectively. After another 60 -min $37^{\circ} \mathrm{C}$ incubation, plates were washed and substrate was added for $30 \mathrm{~min}$ at room temperature and $\mathrm{OD}_{405}$ was determined (27). A serum dilution was considered positive if the mean optical density of two $\mathrm{BCH} 4$ cell wells was greater than twice that of BC-coated wells and greater than 0.1 .

mRNA extraction, Northern blotting, and cytokine detection. Lungs were removed promptly and quick-frozen in liquid nitrogen before storage at $-70^{\circ} \mathrm{C}$. Tissues were then homogenized in $4 \mathrm{M}$ GITC working solution (30) by a Tissumizer (Tekmar Co., Cincinnati, $\mathrm{OH}$ ). The total RNA was extracted and polyA RNA isolated on oligo (dT) cellulose (GIBCO BRL, Gaithersburg, MD) as previously described (30). The polyA mRNA was electrophoretically separated through a $1.5 \%$ agarose denaturing gel and transferred to Zetabind membrane (Cuno Inc., Meriden, CT). Membranes were treated with $160 \mathrm{~mJ}$ of UV light (Stratlinker 1600 , Stratagene, La Jolla, CA) and baked at $80-100^{\circ} \mathrm{C}$ for $2 \mathrm{~h}$. Hybridization with ${ }^{32} \mathrm{P}$ oligonucleotide probes for IL-4, IFN- $\gamma$, and $\alpha$-tubulin was performed as previously described (23). After washing, membranes were exposed to Kodak X-omat film at $-70^{\circ} \mathrm{C}$. Laser densitometry was performed with an LKB UltroScan XL using GelScan XL software (Pharmacia Fine Chemicals, Piscataway, NJ).

Cytotoxicity $T$ cell assays. Lungs were harvested $7 \mathrm{~d}$ after live RSV challenge and lymphocytes were derived by mashing lung tissues between the frosted ends of two sterile glass microscope slides in RPMI containing 10\% FBS. Cells were separated from lung capsules then the suspension was layered on a 3-ml cushion of Ficoll-Hypaque (1.09 specific gravity) and centrifuged at room temperature for $20 \mathrm{~min}$ at $1500 \mathrm{~g}$. The lymphocyte band was aspirated, washed twice, and resuspended in RPMI containing 10\% FBS. As the effector cells were being prepared, $\mathrm{BCH} 4$ and $\mathrm{BC}$ target cells were incubated with ${ }^{51} \mathrm{Cr}(100$ $\mu \mathrm{Ci} / 10^{7}$ cells) for $60 \mathrm{~min}$ at $37^{\circ} \mathrm{C}$, washed three times in $10 \%$ EMEM, and distributed in v-bottom 96-well plates (Costar Corp., Cambridge, MA) at $2 \times 10^{4}$ cells in $100 \mu \mathrm{l}$ per well. Different numbers of lung lymphocytes suspended in $100 \mu \mathrm{l}$ of $10 \% \mathrm{RPMI}$ were added, and the plate was centrifuged at $150 \mathrm{~g}$ for $30 \mathrm{~s}$ before incubation at $37^{\circ} \mathrm{C}$ for 4 h. The cells were gently pelleted and $100 \mu \mathrm{l}$ of the supernatant was transferred and counted in a gamma counter. The spontaneous and total release were obtained by treating the target cells with 10\% RPMI and $5 \%$ Triton X-100 detergent, respectively. The specific release of ${ }^{51} \mathrm{Cr}$ from target cells is defined as $100 \times$ (sample cpm - background cpm)/ (total cpm - background cpm) $(31,32)$.

Definition of CTL effector phenotype. Lymphocytes from the lungs of six mice in each experimental group on day 7 after challenge were pooled. The pooled effector cells were differentially depleted of certain phenotypes then used in a direct CTL assay without in vitro stimulation against ${ }^{51} \mathrm{Cr}$-labeled $\mathrm{BCH} 4$ targets. An immunomagnetic separation method (33) was used for depleting CD4+, CD8+, or both. The conjugated magnetic beads were prepared $1 \mathrm{~d}$ before depletion. $0.5 \mathrm{ml}$ of DYNABEADS M-450 sheep anti-rat IgG (Dynal Inc., Great Neck, NY) were incubated with $5 \mu \mathrm{g}$ of purified rat anti-L3T4, anti-Lyt 2 (Boehringer Mannheim Biochemicals, Indianapolis, IN), and both were kept at $4^{\circ} \mathrm{C}$ for $45 \mathrm{~min}$ with bidirectional mixing, respectively. The conjugated beads were collected by a Dynal Magnetic Particle Concentrator (MPC), washed 4 times by PBS containing 5\% FBS, and resuspended in $1 \mathrm{ml}$ by PBS containing 5\% FBS. $1 \times 10^{7}$ isolated lung lymphocytes were incubated with the conjugated magnetic beads at $4^{\circ} \mathrm{C}$ for 45 min with bidirectional mixing. The depletion was completed by the Dynal MPC and cell suspensions were used for CTL activity after verification of purity by FACS analysis.

Lung T lymphocyte FACS analysis. Lung lymphocytes with different in vitro depletions were adjusted to a concentration of $5 \times 10^{5}$ cells/ $\mathrm{ml}$ then labeled with FITC-conjugated antibody against Lyt2, PE-conjugated antibody against L3T4 (Boehringer Mannheim Biochemicals, Indianapolis, IN), and APC-conjugated antibody against Thy1.2 (Caltag Labs., San Francisco, CA) by incubation for $60 \mathrm{~min}$ at $37^{\circ} \mathrm{C}$. Cells were washed twice in PBS containing 5\% FBS, fixed by paraformaldehyde, and analyzed on a Coulter Epic 753 fluorescent activated cell sorter (FACS; Becton Dickinson Immunocytometry Systems, Mountain View, CA).

\section{Results}

The cytokine expression patterns and illness outcome. In a pilot experiment, monoclonal antibody 11B11 was administered intraperitoneally at $200 \mu \mathrm{g} /$ dose for three successive days, starting at $1 \mathrm{~d}$ before immunization. Mice were challenged with live virus 4 wk after immunization. Anti-IL-4 treatment resulted in significant reduction in illness, with reduced weight loss compared to the control mice (Fig. 1). The same reduction in illness was shown when measured by clinical illness scores (data not shown). The viral replication in lungs $4 \mathrm{~d}$ after challenge was reduced about fivefold by anti-IL-4 treatment $(5.84 \pm 0.46 \mathrm{pfu} /$ gram lung), compared to that in control mice (6.59 $\pm 0.21, P$ $=0.04$ ). A significant reduction of IL-4 and slight increase of IFN- $\gamma$ was observed in the cytokine mRNA expression patterns 


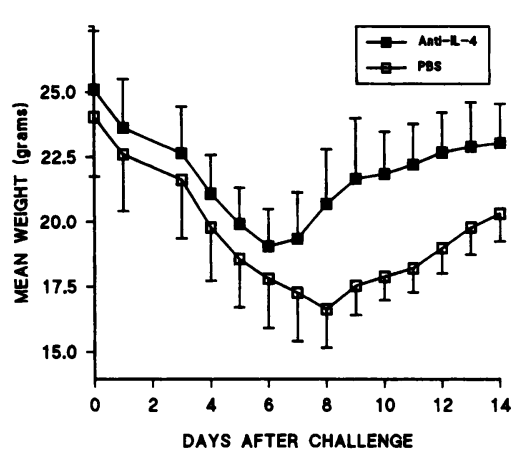

Figure 1. Anti-IL-4 treatment at the time of immunization reduces illness after RSV challenge. Mice (five per group) were immunized with inactivated whole virus and 4 wk later were challenged with live virus. They were treated with anti-IL-4 or PBS for three successive days starting at $1 \mathrm{~d}$ before immunization. Data for weight change are shown as arithmetic means \pm SD. in lungs harvested at $4 \mathrm{~d}$ after challenge (Fig. 2). These data suggest that anti-IL-4 treatment at the time of immunization affected mRNA expression in lungs at the time of remote virus challenge, and may have affected illness by influencing the composition of the immune response.

We next asked whether anti-IL-4 treatment at the time of challenge would influence outcome in the same way, or whether the ultimate composition of the immune response was established at the time of initial antigen exposure. The length of anti-IL-4 treatment was increased for this experiment. Mice were immunized and challenged in the same way and treated with anti-IL-4 on five successive days, starting $1 \mathrm{~d}$ before immunization and/or challenge. When anti- $\mathrm{IL}-4$ treatment was given at the time of immunization, the cytokine mRNA expression patterns in lungs harvested at $4 \mathrm{~d}$ after challenge revealed about threefold reduction of $\mathrm{IL}-4$ and twofold increase of IFN- $\gamma$

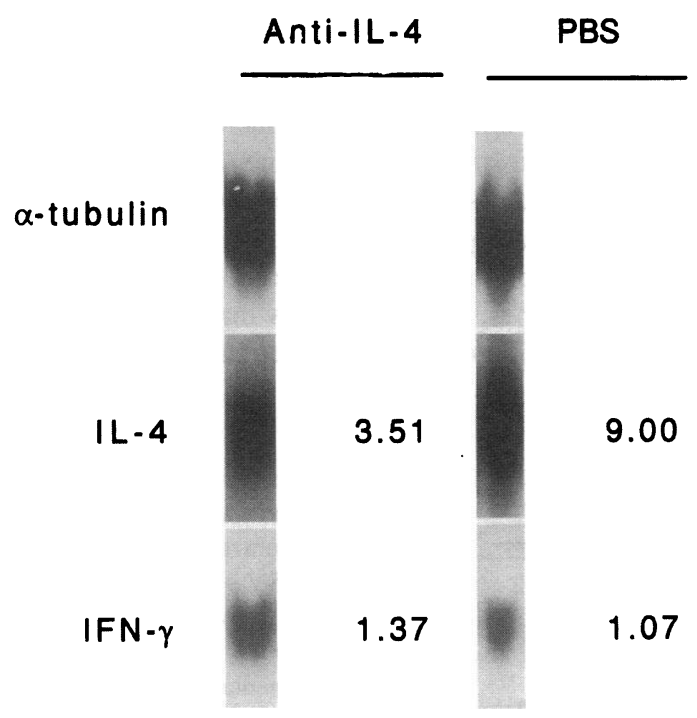

Figure 2. Anti-IL-4 treatment at the time of immunization alters the cytokine expression patterns after RSV challenge. Mice were immunized with inactivated whole virus and 4 wk later were challenged with live virus. They were treated with anti-IL-4 or PBS for three successive days starting at $1 \mathrm{~d}$ before immunization. Cytokine mRNA Northern blot (two lungs per sample) is shown adjacent to results of $\alpha$-tubulinnormalized densities.

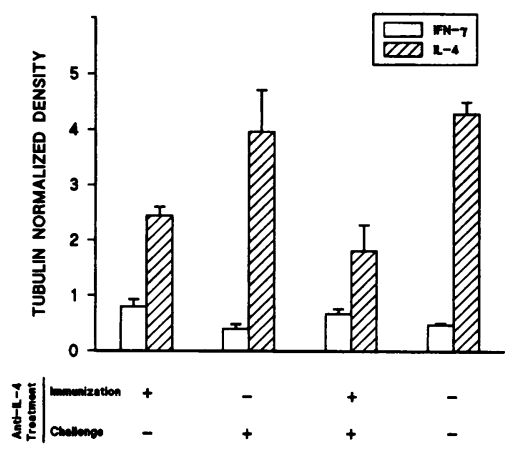

Figure 3. Anti-IL-4 treatment at the time of immunization diminishes IL-4 expression after RSV challenge. Mice were primed with inactivated virus 4 wk before challenge. Anti-IL-4 was administered at the time of immunization, challenge, both time points, and none, respectively. $\alpha$-tubulin-normalized density derived from Northern blots (three samples per group) are given as arithmetic mean \pm SD.

mRNA expression compared to PBS-treated controls (Fig. 3). In addition, the weight loss $(P=0.01)$ and illness scores $(P<$ 0.01 ) at day 8 were significantly reduced by anti-IL-4 treatment given at the time of immunization (Fig. 4), and viral replication was also significantly reduced in lungs $4 \mathrm{~d}$ after challenge (Fig. $4, P=0.03$ ). However, treatment of mice with anti-IL-4 at the time of challenge had no effect on cytokine mRNA patterns (Fig. 3) or illness (Fig. 4).

RSV-specific serum immunoglobulin isotypes. RSV-specific immunoglobulin responses were measured to determine whether a physiological consequence resulted from the altered pattern of cytokine mRNA expression. RSV-specific IgA, $\operatorname{IgG}_{3}$, and IgE remained at levels undetectable in both anti-IL-4 treated and control mice (data not shown). However, in serum samples collected $1 \mathrm{~d}$ before live virus challenge, $\operatorname{IgG}_{2 \mathrm{a}}$ and total Ig titers were much higher in the anti-IL-4 treated mice than the control mice $\left(P=0.01\right.$ for $\operatorname{IgG}_{2 \mathrm{a}}, P=0.04$ for total $\mathrm{Ig})$, while no significant difference in $\operatorname{IgG}_{1}$ titers $(P>0.05)$ was found (Fig. 5). Samples collected $4 \mathrm{wk}$ after challenge showed that $\operatorname{IgG}_{1}, \operatorname{IgG}_{2 \mathrm{a}}$, and total $\mathrm{Ig}$ reached high titers, with no difference between anti-IL-4 treated and control mice (Fig. 5). Anti-IL-4 treatment at the time of challenge had no influence on immunoglobulin subsets (Fig. 5). Taken together, our data suggests that interference with IL- 4 activity at the time of immunization results in a shift from a dominant Th2-like pattern

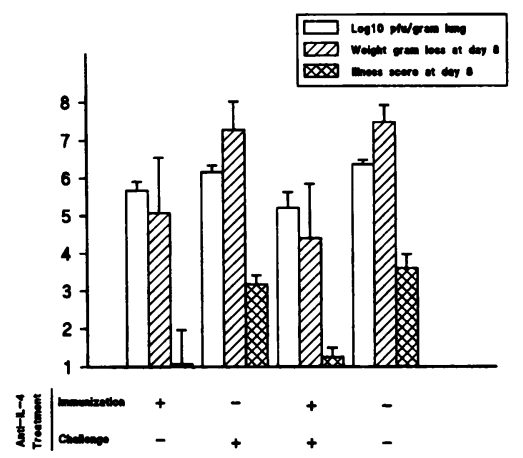

Figure 4. Anti-IL-4 treatment at the time of immunization reduces illness and virus replication in lungs after RSV challenge. Mice immunized with inactivated virus were challenged after 4 wk with live virus. The virus replication levels ( $\log _{10}$ pfu/gram) in lungs $4 \mathrm{~d}$ after challenge (four mice per group), weight loss and illness score $8 \mathrm{~d}$ after challenge (5-6 mice per group) are given as geometric means \pm SD. 


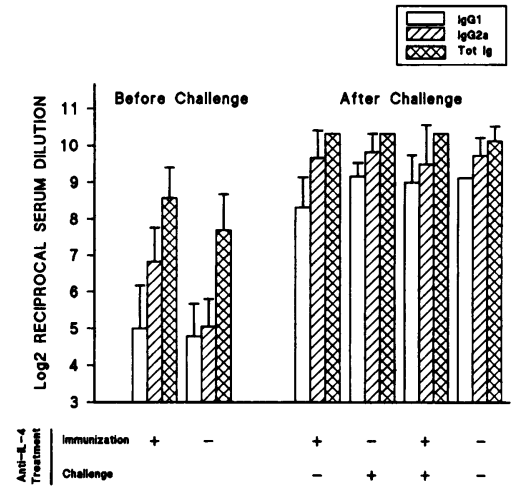

Figure 5. RSV-specific serum immunoglobulin isotypes before and after RSV challenge. Mouse serum samples $(5-6$ per group) were collected at $1 \mathrm{~d}$ before and $28 \mathrm{~d}$ after challenge. Titers are expressed as the mean reciprocal serum dilution \pm SD. Values of $<1: 40$ were assigned the value 1:20 for statistical calculations.

to a more Th1-like response while interference at the time of challenge has no effect.

$R S V$-specific cytotoxicity activity. ${ }^{51} \mathrm{Cr}$ release assays were performed to define factors associated with diminished illness. A direct CTL assay using lung lymphocytes was employed that does not include in vitro stimulation (32). Using this method, CTL activity was detected on day 7 after primary live RSV challenge (Fig. 6). In mice treated with anti-IL-4 at the time of immunization, CTL activity was increased above that in immunized mice that did not receive anti-IL-4. This result was repeated in two consecutive experiments. The activity was RSVspecific and lysed only syngeneic RSV-infected target cells. The phenotype of lymphocytes responsible for the cytolytic activity was then determined in another independent experiment by an immunomagnetic method to deplete CD4+, CD8+, or both in vitro before incubating effectors with targets. FACS analysis showed that $85-89 \%$ of CD4+ and $82-86 \%$ of CD3+ cells were effectively depleted by this method (data not shown). CD8+ depletion abolished CTL activity, while CD4+ depletion did not affect CTL activity (data not shown). The FACS data of the total lung lymphocyte population also showed that the proportion of CD8+ lymphocytes was greater in the anti-IL4 treated group than that in the PBS-treated group (10.6\% compared to $3.4 \%$, respectively). These data suggest that anti-IL4 treatment at the time of immunization resulted in augmented CD8 + CTL activity following subsequent live RSV challenge.

\section{Discussion}

We report here that upon live RSV challenge, mice treated with anti-IL-4 neutralizing monoclonal antibody at the time of formalin-inactivated whole RSV immunization showed diminished illness and reduced RSV replication, associated with a shift from a Th2-like to a Th1-like pattern of cytokine expression. The anti-IL-4 treatment also resulted in an augmented RSV-specific CD8+ CTL activity in lung lymphocytes. These results suggest that interference with IL- 4 activity at the time of immunization can alter the cytokine milieu at the time of subsequent RSV challenge, resulting in modulation of effector functions and improvement in illness outcome.

The improved illness outcome and reduced RSV replication in lungs after challenge when anti-IL-4 was administered at the time of immunization was associated with an increased expression of IFN- $\gamma$ and a reduced expression of IL-4. While the shift in cytokine mRNA expression was subtle, the increase in $\mathrm{RSV}$-specific $\operatorname{IgG}_{2 \mathrm{a}}$ supports the conclusion that a shift from a dominant Th2-like pattern to a more Th1-like response indeed occurred. We believe a major advantage in measuring cytokine mRNA expression by direct Northern blotting is the increased confidence that subtle changes are real, without the possible distortion of in vitro stimulation.

The treatment with anti-IL-4 was only effective when given at the time of initial RSV antigen presentation. Thus, the nature of the primary immune response to RSV antigens can determine the composition of the response to subsequent challenge. As in other models of infectious pathogens, a more Th1-like pattern of cytokine expression was associated with reduced RSV-induced illness $(13,15,16,24)$. This suggests that defining mechanisms of modulating initial immune responses to vaccines to be more Th1-like may have broad application.

The Th1/Th2 paradigm has been important in organizing theories about regulation of subsequent effector responses. However, CD4+ T helper lymphocytes are not the only cells in the inflammatory response producing cytokines. The cytokine environment is also determined by epithelial cells, macrophages, B lymphocytes, CD8+ lymphocytes, NK cells, and $\gamma \delta$ T lymphocytes. Many of these cells secrete cytokines that overlap with those of the classical Th1 and Th2 Thelper lymphocyte subsets. In this study, we found that CD8 + CTL activity was augmented at the time of RSV challenge in mice treated with anti-IL-4 at the time of immunization. This suggests the possibility that the shift to a Th1 cytokine expression pattern was actually the result of increased CD8+ lymphocyte activity. Defining the phenotype of cells which produce the complex cytokine milieu will be important for understanding how immune responses are regulated, and for devising new strategies to modulate vaccine-induced immune responses.

Ultimately, the goal of any vaccine is to prevent illness associated with subsequent exposure to the pathogen. Therefore, it is not only important to define the cells producing the cytokine milieu, but to define the effector mechanisms that respond to the vaccine-induced conditions. It is the effector mechanisms that more directly translate into protection from or enhancement of disease. Th2-mediated responses may be detrimental to the host, initiating mechanisms such as mast cell activation and the release of histamine and other soluble factors that promote inflammation and altered smooth muscle tone (34). In contrast, Th1-type cytokines may stimulate more favorable effector mechanisms. IgG $_{2 a}$, whose production is stimulated by Thl responses, has better complement-binding and Fc-binding properties than other Ig isotypes. These qualities may improve neutralizing capacity or facilitate viral clearance through antibody-

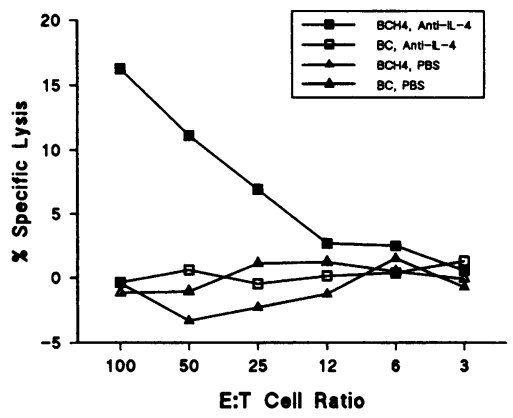

Figure 6. Anti-IL-4 treatment at the time of immunization enhances RSV-specific cytotoxic activity after RSV challenge. This shows a representative experiment in which lymphocytes from the lungs of four mice were used as effectors. ${ }^{51} \mathrm{Cr}$-labeled BCH4 target cells were used in a direct measure of RSV-

specific cytotoxic activity that did not include in vitro stimulation of effectors. Each point represents the mean from three replicate wells. 
dependent cell-mediated cytotoxicity (ADCC) mechanisms. There may also be modulating effects on other limbs of the immune response. For instance, increased expression of $\mathrm{MHC}$ molecules stimulated by IFN- $\gamma$ (35) may facilitate antigen presentation in general and lead to more rapid generation of effector mechanisms and clearance of virus-infected cells.

The increased RSV-specific $\operatorname{IgG}_{2 \mathrm{a}}$ titers before challenge in the anti-IL-4 treated group may reflect isotype switching by increased IFN- $\gamma$ levels. However, a complementary decrease in the IgG $_{1}$ isotype was not seen, and the isotype profile in all groups was similar after challenge. We therefore believe the cytokine milieu influenced effector mechanisms other than antibody to clear virus earlier and reduce illness. We have shown that RSV-specific CD8 + CTL activity was augmented in antiIL-4 treated mice $7 \mathrm{~d}$ after live RSV challenge. The assay was a direct measure of CTL activity in lung at a moment-in-time without in vitro stimulation of effectors. In three successive experiments, mice treated with anti-IL-4 at the time of inactivated RSV immunization had increased RSV-specific cytotoxic activity in lungs after RSV challenge. The increased CTL response was associated with decreased illness. The augmented cytotoxic activity, moreover, was specific for the CD8+ phenotype. The formalin-inactivated RSV immunization would not be expected to induce CD8+, MHC class I-restricted CTL because, as a nonreplicating antigen, it should be processed and presented via MHC class II molecules. Thus, our hypothesis is that the anti-IL-4 treatment shifted the cytokine environment to one favorable to more rapid induction of CTL activity in response to the live RSV challenge. Defining the factors associated with the rapid induction of CTL activity is the subject of ongoing work in our laboratory.

Cytotoxic $\mathrm{T}$ lymphocytes are known to be important in the clearance of many viruses including RSV $(20,31-32,36-38)$. Passive transfer experiments utilizing CD8+ RSV-specific T cells have been shown to effectively clear RSV (39). Transfer of higher doses of RSV-specific CTL in mice has caused a hemorrhagic pneumonitis in some studies (40), but not others (41). Recently, it has been shown that the specificity of the CTL effectors and the $T$ cell environment in which they are present can affect the type of lung pathology caused by RSV (42). We have shown that in vivo induction of RSV-specific $\mathrm{CD8}+\mathrm{CTL}$ is associated with rapid viral clearance and reduced illness. We suspect these CD8+ CTL were part of the primary response to live RSV challenge and were not memory CTL induced directly by vaccine. In these experiments the CTL activity was only measured at one time point. Therefore, it is possible that peak CTL activity after challenge was not higher, but rather developed more rapidly in the vaccine-induced cytokine milieu produced by anti-IL- 4 treatment.

Our data indicate that interfering with $\mathrm{IL}-4$ activity at the time of immunization can affect the composition of the immune response and reduce illness after subsequent RSV challenge. These findings may be relevant to understanding how a formalininactivated RSV vaccine resulted in enhanced illness in children subsequently infected with RSV (1-4). Learning how to modulate the immune response to viral pathogens by selectively activating $T$ cell populations at the time of immunization has the potential to increase vaccine efficacy and improve vaccine safety.

\section{Acknowledgments}

We thank Frances W. Robinson for technical assistance, Wayne F. Green and Bruce W. Greig for helping run the FACS analysis, and Peter F. Wright and David T. Karzon for reading the paper.
This work was supported by funding from the World Health Organization, and in part by the National Institutes of Health contract NO1AI-05050 and grant R01-33933.

\section{References}

1. Kapikian, A. Z., R. H. Mitchell, R. M. Chanock, R. A. Shvedoff, and C. E. Stewart. 1969. An epidemiologic study of altered clinical reactivity to respiratory syncytial (RS) virus infection in children previously vaccinated with an inactivated RS virus vaccine. Am. J. Epidemiol. 89:405-421.

2. Kim, H. W., J. G. Canchola, C. D. Brandt, G. Pyles, R. M. Chanock, K. Jensen, and R. H. Parrott. 1969. Respiratory syncytial virus disease in infants despite prior administration of antigenic inactivated vaccine. Am. J. Epidemiol. 89:422-434.

4. Fulginiti, V. A., J. J. Eller, O. F. Sieber, J. W. Joyner, M. Minamitani, and G. Meiklejohn. 1969. Respiratory virus immunization - A field trial of two inactivated respiratory virus vaccines; an aqueous trivalent parainfluenza virus vaccine and an alum-precipitated respiratory syncytial virus vaccine. Am. J. Epidemiol. 89:435-448.

4. Chin, J., R. L. Magoffin, L. A. Shearer, J. H. Schieble, and E. H. Lennette. 1969. Field evaluation of a respiratory syncytial virus vaccine and a trivalent parainfluenza virus vaccine in a pediatric population. Am. J. Epidemiol. 89:449463.

5. Kim, W. H., J. O. Arrobio, C. D. Brandt, P. F. Wright, D. Hodes, R. M. Chanock, and R. H. Parrott. 1973. Safety and antigenicity of temperature sensitive (TS) mutant respiratory syncytial virus (RSV) in infants and children. Pediatrics. 52:56-63.

6. Wright, P. F., R. B. Belshe, H. W. Kim, L. P. Van Voris, and R. M. Chanock. 1982. Administration of a highly attenuated, live respiratory syncytial virus vaccine to adults and children. Infect. Immun. 37:397-405.

7. Friedewald, W. T., B. R. Forsyth, C. B. Smith, M. A. Gharpure, and R. M. Chanock. 1968. Low-temperature-grown RS virus in adult volunteers. JAMA (J. Am. Med. Assoc.) 204:142-146.

8. Kim, W. H., J. O. Arroio, G. Pyles, C. D. Brandt, E. Camargo, R. M. Chanock, and R. H. Parrott. 1971. Clinical and immunological response of infants and children to administration of low-temperature adapted respiratory syncytial virus. Pediatrics. 48:745-755.

9. Mosmann, T. R., and R. I. Coffman. 1987. Two types of mouse T helper cell clone: implication for immune regulation. Immunol. Today. 8:223-226.

10. Mosmann, T. R., and R. I. Coffman. 1989. Th1 and Th2 cells: different pattern of lymphokine secretion lead to different functional properties. Annu. Rev. Immunol. 7:145-173.

11. Scott, P., R. Natovitz, R. L. Coffman, E. Pearce, and A. Sher. 1988. Immunoregulation of cutaneous leishmaniasis. $T$ cell lines that transfer protective immunity or exacerbation belong to different $T$ helper subsets and respond to distinct parasite antigens. J. Exp. Med. 168:1675-1684.

12. Heinzel, F. P., M. D. Sadick, B. J. Holaday, R. L. Coffman, and R. M. Locksley. 1989. Reciprocal expression of interferon- $\gamma$ or interleukin 4 during the resolution or progression of murine leishmaniasis. Evidence of expansion of distinct helper T cell subsets. J. Exp. Med. 169:59-72.

13. Gazzinelli, R. T., F. T. Hakin, S. Hieny, G. M. Shearer, and A. Sher. 1991. Synergistic role of CD4+ and CD8 + T lymphocytes in IFN- $\gamma$ production and protective immunity induced by an attenuated Toxoplasma gondii vaccine. J. Immunol. 146:286-292.

14. Sher, A., R. L. Coffman, S. Hieny, and A. W. Cheever. 1990. Ablation of eosinophil and IgE responses with anti-IL-5 or anti-IL-4 antibodies fails to affect immunity against Schistosoma mansoni in the mouse. J. Immunol. 145:3911-3916.

15. Romani, L., S. Mocci, C. Bietta, L. Lanfaloni, P. Puccetti, and F. Bistoni. 1991. Th1 and Th2 cytokine secretion patterns in murine candidiasis: association of Th1 responses with acquired resistance. Infect. Immun. 59:4647-4654.

16. Kanagawa, O., B. A. Vaupel, S. Gayama, G. Koehler, and M. Kopf. 1993. Resistance of mice deficient in IL-4 to retrovirus-induced immunodeficiency syndrome (MAIDS). Science (Wash. DC). 262:240-242.

17. Yamamura, M., K. Uyemura, R. J. Deans, K. Weinberg, T. H. Rea, B. R. Bloom, and R. L. Modlin. 1991. Defining protective responses to pathogens: cytokine profiles in leprosy lesions. Science (Wash. DC). 254:277-279.

18. Griffin, D. E., and B. J. Ward. 1993. Differential CD4 T cell activation in measles. J. Infect. Dis. 168:275-281.

19. Clerici, M., F. T. Hakim, D. J. Venzon, S. Blatt, C. W. Hendrix, T. A. Wynn, and G. M. Shearer. 1993. Changes in interleukin-2 and interleukin-4 production in asymptomatic, human immunodeficiency virus-seropositive individuals. J. Clin. Invest. 91:759-765.

20. Graham, B. S., L. A. Bunton, P. F. Wright, and D. T. Karzon. 1991. Role of $T$ lymphocyte subsets in the pathogenesis of primary infection and rechallenge with respiratory syncytial virus in mice. J. Clin. Invest. 88:1026-1033.

21. Connors, M., A. B. Kulkarni, C.-Y. Firestone, K. L. Holmes, H. C. Morse III, A. V. Sotnikov, and B. R. Murphy. 1992. Pulmonary histopathology induced 
by respiratory syncytial virus (RSV) challenge of formalin-inactivated RSVimmunized BALB/c mice is abrogated by depletion of CD4+ T cells. J. Virol. 66:7441-7451.

22. Alwan, W. H., F. M. Record, and P. J. M. Openshaw. 1993. Phenotypic and functional characterization of $\mathrm{T}$ cell lines specific for individual respiratory syncytial virus proteins. J. Immunol. 150:5211-5218.

23. Graham, B. S., G. S. Henderson, Y.-W. Tang, X. Lu, K. M. Neuzil, and D. C. Colley. 1993. Priming immunization determines T helper cytokine mRNA expression patterns in lungs of mice challenged with respiratory syncytial virus. J. Immunol. 151:2032-2040.

24. Sadick, M. D., F. P. Heinzel, B. J. Holaday, R. T. Pu, R. S. Dawkins, and R. M. Locksley. 1990. Cure of murine leishmaniasis with anti-interleukin 4 monoclonal antibody. Evidence for a T cell-dependent, interferon $\gamma$-independent mechanism. J. Exp. Med. 171:115-127.

25. Gross, A., S. Z. Ben-Sasson, and W. E. Paul. 1993. Anti-IL-4 diminishes in vivo priming for anti-specific IL-4 production by $\mathrm{T}$ cells. J. Immunol. 150:2112-2120.

26. Kopf, M., G. Le Gros, M. Bachmann, M. C. Lamers, H. Bluethmann, and G. Kohler. 1993. Disruption of the murine IL-4 gene blocks Th2 cytokine responses. Nature (Lond.). 362:245-248.

27. Graham, B. S., L. A. Bunton, P. F. Wright, and D. T. Karzon. 1991. Reinfection of mice with respiratory syncytial virus. J. Med. Virol. 34:7-13.

28. Graham, B. S., L. A. Bunton, J. Rowland, P. F. Wright, and D. T. Karzon. 1991. Respiratory syncytial virus in anti- $\mu$ treated mice. $J$. Virol. 65:4936-4942.

29. O'Hara, J., and W. E. Paul. 1985. B cell stimulatory factor (BSF-1): production of a monoclonal antibody and molecular characterization. Nature (Lond.). 315:333-336.

30. Henderson, G. S., J. T. Conary, J. M. Davidson, S. J. Stewart, F. S. House, and T. L. McCurley. 1991. A reliable method for Northern blot analysis using synthetic oligonucleotide probes. Biotechniques. 10:190-197.

31. Bangham, C. R. M., M. J. Cannon, D. T. Karzon, and B. A. Askonas. 1985. Cytotoxic T-cell response to respiratory syncytial virus in mice. J. Virol. 56:55-59.
32. Taylor, G., E. J. Stott, and A. J. Hayle. 1985. Cytotoxic lymphocytes in the lungs of mice infected with respiratory syncytial virus. J. Gen. Virol. 66:25332538.

33. Brun, A., G. Gaudernack, and S. Sandberg. 1990. A new method for the isolation of reticulocytes: Positive selection of human reticulocytes by immunomagnetic separation. Blood. 76:2397-2403.

34. Galli, S. J. 1993. New concepts about the mast cell. N. Engl. J. Med. 328:257-265.

35. Maziarz, R. T., S. J. Mentzer, S. J. Burakoff, and D. V. Faller. 1990 Distinct effects of interferon- $\gamma$ and MHC class I surface antigen levels on resistance of the K562 tumor cell line to natural killer-mediated lysis. Cell. Immunol. 130:329-338.

36. Issacs, D., C. R. M. Bangham, and A. J. McMichael. 1987. Cell-mediated cytotoxic response to respiratory syncytial virus in infants with bronchiolitis Lancet. ii:769-771.

37. Nicholas, J. A., K. L. Rubino, M. E. Levely, E. G. Adams, and P. L. Collins. 1990. Cytolytic T-lymphocyte responses to respiratory syncytial virus: Effector cell phenotype and target proteins. J. Virol. 64:4232-4241.

38. Cherrie, A. H., K. Anderson, G. W. Wertz, and P. J. M. Openshaw. 1992. Human cytotoxic $T$ cells stimulated by antigen on dendritic cells recognize the $\mathrm{N}, \mathrm{SH}, \mathrm{F}, \mathrm{M}, 22 \mathrm{~K}$, and $1 \mathrm{~b}$ proteins of respiratory syncytial virus. J. Virol. 66:2102-2110

39. Cannon, M. J., E. J. Stott, G. Taylor, and B. A. Askonas. 1987. Clearance of persistent respiratory syncytial virus infections in immunodeficient mice following transfer of primed T cells. Immunology. 62:133-138.

40. Cannon, M. J., P. J. M. Openshaw, and B. A. Askonas. 1988. Cytotoxic $\mathrm{T}$ cells clear virus but augment lung pathology in mice infected with respiratory syncytial virus. J. Exp. Med. 168:1163-1168.

41. Muñoz J. L., C. A. McCarthy, M. E. Clark, and C. B. Hall. 1991. Respiratory syncytial virus infection in C57BL/6 mice: Clearance of virus from the lungs with virus-specific cytotoxic T cells. J. Virol. 65:4494-4497.

42. Alwan W. H., W. J. Kozlowska, and P. J. M. Openshaw. 1994. Distinct types of lung disease caused by functional subsets of antiviral T cells. J. Exp. Med. 179:81-89. 